\title{
Confirmation that the AKT1 (rs2494732) Genotype Influences the Risk of Psychosis in Cannabis Users
}

\author{
Marta Di Forti, Conrad lyegbe, Hannah Sallis, Anna Kolliakou, M. Aurora Falcone, Alessandra Paparelli, \\ Miriam Sirianni, Caterina La Cascia, Simona A. Stilo, Tiago Reis Marques, Rowena Handley, \\ Valeria Mondelli, Paola Dazzan, Carmine Pariante, Anthony S. David, Craig Morgan, John Powell, and \\ Robin M. Murray
}

Background: Cannabis use is associated with an increased risk of psychosis. One study has suggested that genetic variation in the AKT1 gene might influence this effect.

Methods: In a case-control study of 489 first-episode psychosis patients and 278 control subjects, we investigated the interaction between variation at the AKT1 rs2494732 single nucleotide polymorphism and cannabis use in increasing the risk of psychosis.

Results: The rs 2494732 locus was not associated with an increased risk of a psychotic disorder, with lifetime cannabis use, or with frequency of use. We did, however, find that the effect of lifetime cannabis use on risk of psychosis was significantly influenced by the rs 2494732 locus (likelihood ratio statistic for the interaction $=8.54 ; p=.014$ ). Carriers of the C/C genotype with a history of cannabis use showed a greater than twofold increased likelihood of a psychotic disorder (odds ratio $=2.18$ [95\% confidence interval: $1.12,4.31]$ ) when compared with users who were T/T carriers. Moreover, the interaction between the rs 2494732 genotype and frequency of use was also significant at the $5 \%$ level (likelihood ratio $=13.39 ; p=.010$ ). Among daily users, $\mathrm{C} / \mathrm{C}$ carriers demonstrated a sevenfold increase in the odds of psychosis compared with $\mathrm{T} / \mathrm{T}$ carriers (odds ratio $=7.23$ [95\% confidence interval: $1.37,38.12]$ ).

Conclusions: Our findings provide strong support for the initial report that genetic variation at rs 2494732 of $A K T 1$ influences the risk of developing a psychotic disorder in cannabis users.

Key Words: AKT1 gene, cannabis use, gene $\times$ environment interaction, psychosis, schizophrenia, signaling pathways

annabis is the most commonly used illicit drug in the world (1). Most people who use it come to no harm. However, it has become apparent in recent years that cannabis use is a risk factor for the development of schizophrenia-like psychotic disorders $(2,3)$. Why certain individuals develop psychosis when their peers, who smoke similar amounts of cannabis, remain well is unclear. One suggestion is that such individuals may carry some genetic susceptibility $(4,5)$. Should the genes underlying such susceptibility be identified, this would be of considerable public health importance.

One candidate for a gene $\times$ cannabis interaction is the AKT1 gene, which has been associated with schizophrenia in some but not all studies (6-8). The AKT1 gene is an attractive candidate because it codes for a protein kinase that forms an integral part of the dopamine receptor signaling cascade in the striatum (9). Moreover, in vivo administration to mice of delta-9-tetrahydrocannabinol (delta-9-TCH), the active ingredient in cannabis, activates this signaling cascade via AKT1 phosphorylation $(10,11)$. Furthermore,

From the Departments of Psychosis Studies (MDF, AK, MAF, TRM, PD, ASD, RMM); Neuroscience (Cl, AP, JP); and Biostatistics (HS), Institute of Psychiatry, Kings College London, London, United Kingdom; Department of Psychiatry (MS), Catanzaro Medical School, Catanzaro; and Department of Psychiatry and Neuroscience (CLC), Palermo University, Palermo, Italy; and Departments of Health Services and Public Health (SAS, RH, CM) and Psychological Medicine (VM, CP), Institute of Psychiatry, Kings College London, London, United Kingdom.

Address correspondence to Marta Di Forti, M.D., Ph.D., Kings College London, Department of Psychosis Studies, Institute of Psychiatry, De Crespigny Park, London SE5 8AF, United Kingdom; E-mail: marta.diforti@ kcl.ac.uk.

Received Mar 29, 2012; revised Jun 5, 2012; accepted Jun 6, 2012. van Winkel et al. (12) studied 801 patients with schizophrenia and 740 of their siblings and reported that subjects who carried two copies of the $C$ allele of the rs 2494732 polymorphism of the AKT1 gene were especially at risk of schizophrenia and schizotypy, respectively, if they used cannabis. In a separate study, van Winkel et al. (13) also reported an AKT1-cannabis interaction on cognitive performance. Among psychotic patients who used cannabis, carriers of the AKT1 rs2494732 C/C genotype did significantly worse on a test of sustained attention compared with $T / T$ carriers (13). Moreover, a neuroimaging study showed that healthy subjects carrying the dopamine transporter 9-repeat and the AKT1 rs130233 G/G genotype had the greatest psychotic response and striatal activation following administration of delta-9-THC (14).

A recent critical review of gene $\times$ environment $(G \times E)$ research in psychiatry concluded that direct replications deserve more attention than novel findings or indirect replications (15). We therefore set out to directly test the veracity of the AKT1 rs $2494732 \times$ cannabis interaction in a sample of patients with their first episode of psychosis and healthy control subjects in south London. Because of this a priori hypothesis, rs 2494732 was the only locus genotyped and tested for interaction with cannabis use.

\section{Methods and Materials}

\section{Participants}

Participants were part of the Genetic and Psychotic Disorders Study case-control project that approached all patients aged 18 to 65 years who presented with their first episode of psychosis to the Lambeth, Southwark, and Croydon adult inpatient units of the South London and Maudsley National Health Service Foundation Trust between December 2005 and October 2010. Patients who met ICD-10 criteria for a diagnosis of nonorganic psychosis (F20F29 and F30-F33) (16), validated by administering the Schedules for Clinical Assessment in Neuropsychiatry (17), were invited to participate in the study. Of the total approached (734), 20\% (145) 
refused to participate and 596 patients experiencing their first episode of psychosis were successfully recruited into the study. The two most common reasons for refusal were a lack of interest in the research and the length of the full assessment.

Over the same time frame, from the area served by the same mental health units, we recruited a sample of 333 healthy control subjects, aged 18 to 65 years, which was broadly similar to the local population in terms of ethnicity, educational attainment, and employment status (18), using internet and newspaper advertisements and distribution of leaflets at train stations, shops, and job centers. None of the material used for advertising mentioned cannabis or illicit drug use. Volunteers willing to take part in the study were administered the Psychosis Screening Questionnaire (19) and were excluded if they met criteria for a psychotic disorder or if they reported a previous diagnosis of psychotic illness.

Further details on the age distribution of the samples and on the diagnostic breakdown of the cases are available in Tables S1 and S2 in Supplement 1.

The data presented in this study are based on the 489 firstepisode psychosis patients ( $82 \%$ of the total recruited) and 278 control subjects ( $83 \%$ of the total recruited) on whom we were able to obtain both a history concerning cannabis use and DNA samples.

\section{General Assessment and Data on Exposure of Interest}

Sociodemographic data (age, gender, self-reported ethnicity, level of education attainment, and employment status) on cases and control subjects were collected using the Medical Research Council Social Scale (20). Participants were asked if they had ever smoked tobacco, and if they drank alcohol, their weekly alcohol unit consumption was recorded. A detailed history of illicit drug use (cannabis, stimulants, and any other recreational drug) was taken using the Cannabis Experience Questionnaire modified version (21). The two measures of exposure to cannabis use included in the analyses were: 1 ) lifetime history of cannabis use, i.e., had the subject ever used cannabis at any point in the lifetime $(\mathrm{No}=0$; Yes $=1)$; and 2) lifetime frequency of cannabis use, i.e., the frequency that characterized the subject's most consistent pattern of use (No $=0$; at weekends or less frequently $=1$; everyday $=2$ ).

\section{Genotyping}

DNA was obtained from all participants that completed the assessment described above (489 cases and 278 control subjects). Seventy-five percent of DNA samples used originated from blood and $25 \%$ from cheek swabs. DNA extraction was performed using standard phenol-chloroform methods.

As the purpose of the study was to explicitly test for interaction at a specific site within $A K T 1$, genotyping focused exclusively on the van Winkel single nucleotide polymorphism (SNP), rs2494732. Off the shelf Taqman assays for this polymorphism are available as a kit, at http://www.appliedbiosystems.com. The specific assay format used can be identified by inputting the corresponding assay ID (C_16191608_10). Genotype calls were discriminated based on algorithmic membership of three clusters representing homozygote $T / T$, heterozygote $C / T$, and homozygote $C / C$ genotype classes. $A$ comparison of genotype results for 360 individuals with overlapping blood and cheek swab DNA revealed there was 100\% concordance between blood- and cheek-derived genotype data.

\section{Validation of Self-report of Ethnicity}

To confirm self-report of ethnicity, genetic ancestry was derived using a panel of 57 ancestry informative genetic markers. These were genotyped using iPLEX technology developed for the MassArray platform (Sequenom Inc., San Diego, California). Further infor- mation on the makeup of the marker panel is available on request. Ancestry scores were derived using the program Structure (22) to implement a model-based (Markov Chain Monte Carlo) clustering algorithm. Having determined the best solution for $\mathrm{K}$ (the probable true number of underlying genetic groups) in initial analyses, individuals who scored between $96 \%$ and $100 \%$ for genetic cluster membership were used to create a three-way ancestral axis based on Black African $(n=81)$, European Caucasian $(n=118)$, and Asian $(n=16)$ ancestry. These reference groups were used to index genetic ancestry for the remaining sample (Figure 1). Eighty-three percent of participants had information on both self-reported ethnicity and ancestry markers. Using $95 \%$ to define the cutoff point for cluster membership resulted in the genetic validation of 241 selfreported ethnicities. The level of overall agreement between selfreported and genetic ethnicities (96\%) was reassuringly high.

\section{Ethics}

This study was part of the GAP study, which was granted ethical approval by the South London and Maudsley and Institute of Psychiatry Local Research Ethics Committee. All cases and control subjects included in the study gave informed written consent, signing the consent document, to the publication of data originating from the study.

\section{Data Analysis}

Data were recorded in SPSS version 15 and analyzed using Stata 11 (Stata, College Station, Texas). Based on the existing literature, a history of 1) ever having used cannabis (referred to hereafter as lifetime cannabis use) and 2) lifetime frequency of use were the main environmental measures of interest. These were analyzed in conjunction with rs2494732. Genotypes at this locus were coded (for initial tests of main effects) to reflect the allele dosage of the SNP of interest selected in accordance with the original report (12): $\mathrm{T} / \mathrm{T}=0 ; \mathrm{C} / \mathrm{T}=1 ; \mathrm{C} / \mathrm{C}=2$. Additional sociodemographic and lifestyle variables (such as ethnicity and other substance misuse) were modeled as potential confounders. Chi-square tests and $t$ tests (or the nonparametric equivalent of these, the Mann-Whitney $U$ test) were used to test for association between potential confounders and both presence of psychotic disorder and genotype. Further, $\chi^{2}$ tests were used to determine whether exposures of interest were

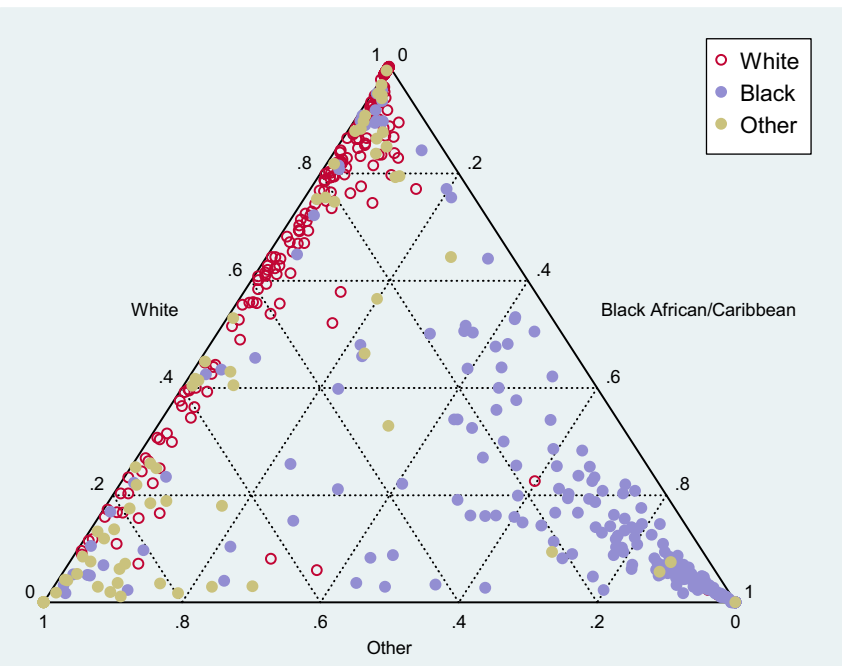

Figure 1. Plots of 3-way ancestral axis based on Black African, European Caucasian and Other. 
associated with $A K T 1$ genotype in control subjects (a signature of gene $X$ environment correlation).

Finally, a logistic regression was used to test for association of candidate genotype and presence of a psychotic disorder after adjusting for various covariates (e.g., gender, ethnicity, and tobacco use), along with either history of lifetime cannabis use or lifetime frequency of use. Analyses were run separately for each exposure and then including an interaction term between the exposure and genotype. The interaction model used examined whether the relationship between AKT1 rs2494732 genotype and presence of psychosis differed as a function of having a history of cannabis use and also explored the possibility of a relationship with frequency of use.

Odds ratios (OR) of psychosis among carriers of the AKT1 rs2494732 C/T and C/C genotypes compared with the T/T genotype, among people with different exposures to cannabis, were calculated from the estimates provided by the model.

\section{Results}

The sample consisted of 489 first episode of psychosis cases (FEP) and 278 control subjects. First episode of psychosis cases were significantly younger (mean age 27.7 years; SD 8.4) than control subjects (mean age 30.2 years; SD 9.5; $p<.001$ ) and, as expected, had a mean premorbid IQ of 6.1 points lower $(p<.0001)$. First episode of psychosis patients were also more likely to belong to the Black African/Caribbean group $(p<.001)$ than control subjects (Table 1).

We obtained AKT1 rs2494732 genotyping data on 485 of 489 FEP and on 276 of 278 control subjects, with an overall call rate of $99 \%$. We found no significant difference in AKT1 rs2494732 allelic distribution by gender $\left(\chi^{2}=4.12 ; p=.128\right)$ or between FEP and control

Table 1. Demographic Characteristics of First Episode Psychosis Patients and Control Subjects

\begin{tabular}{|c|c|c|c|c|}
\hline & $\begin{array}{c}\text { FEP } \\
n=489 \\
\text { Mean (SD) }\end{array}$ & $\begin{array}{c}\text { Control } \\
\text { Subjects } \\
n=278 \\
\text { Mean (SD) }\end{array}$ & $d f^{a}$ & $p$ Value $^{b}$ \\
\hline $\mathrm{Age}^{c}$ & $27.67(8.4)$ & $30.20(9.5)$ & $Z=3.65^{b}$ & $<.001$ \\
\hline Premorbid IQ ${ }^{c}$ & $\begin{array}{c}90.02(10.1) \\
n(\%)\end{array}$ & $\begin{array}{c}98.60(9.6) \\
n(\%)\end{array}$ & 208 & $<.001$ \\
\hline \multicolumn{5}{|l|}{ Gender } \\
\hline Male & $322(66.1)$ & $165(59.8)$ & & \\
\hline Female & 165 (33.9) & $111(40.2)$ & 1 & .080 \\
\hline No details & 2 & 2 & & \\
\hline \multicolumn{5}{|l|}{$\begin{array}{r}\text { Self-Reported } \\
\text { Ethnicity }\end{array}$} \\
\hline White Caucasian & $152(32.3)$ & $146(54.7)$ & & \\
\hline Black Caribbean & $157(33.3)$ & 53 (19.9) & 3 & $<.001$ \\
\hline Black African & $113(24.0)$ & $31(11.2)$ & & \\
\hline Asian/other & 49 (10.4) & $39(14.2)$ & & \\
\hline No details & 18 & 9 & & \\
\hline $\begin{array}{c}\text { AKT1 rs } 2494732 \\
\text { Allelic } \\
\text { Frequency }\end{array}$ & & & & \\
\hline $\mathrm{T} / \mathrm{T}$ & $131(27.0)$ & $84(30.4)$ & & \\
\hline $\mathrm{C} / \mathrm{T}$ & $238(49.1)$ & $133(48.2)$ & 2 & .535 \\
\hline $\mathrm{C} / \mathrm{C}$ & $116(23.9)$ & $59(21.4)$ & & \\
\hline No details & 4 & 2 & & \\
\hline
\end{tabular}

FEP, first episode psychosis patients.

${ }^{a}$ Degrees of freedom.

${ }^{b} p$ values from $t$ tests (or Mann-Whitney $U$ test) and $\chi^{2}$ tests.

'Missing data: 170 control subjects and 380 cases have no premorbid IQ information.
Table 2. Patterns of Drug Use in First Episode Psychosis Patients and Control Subjects

\begin{tabular}{|c|c|c|c|c|}
\hline & $\begin{array}{c}\mathrm{FEP}=489 \\
n(\%)\end{array}$ & $\begin{array}{c}\text { Control } \\
\text { Subjects }=278 \\
n(\%)\end{array}$ & $d f$ & $p$ Value $^{a}$ \\
\hline \multicolumn{5}{|l|}{ Ever Used Tobacco } \\
\hline No & $125(31.4)$ & $127(53.2)$ & 1 & \\
\hline Yes & $271(68.6)$ & $112(46.8)$ & & $<.001$ \\
\hline No details & 93 & 39 & & \\
\hline \multicolumn{5}{|l|}{$\begin{array}{c}\text { Ever Used Other } \\
\text { Stimulants }\end{array}$} \\
\hline No & $201(66.6)$ & $157(72.6)$ & 1 & \\
\hline Yes & $102(33.4)$ & $60(27.4)$ & & .146 \\
\hline No details & 186 & 61 & & \\
\hline \multicolumn{5}{|l|}{ Ever Used Cannabis } \\
\hline No & $180(39.3)$ & $94(37.1)$ & 1 & \\
\hline Yes & $275(60.7)$ & $160(62.9)$ & & .567 \\
\hline No details & 34 & 24 & & \\
\hline \multicolumn{5}{|l|}{$\begin{array}{l}\text { Lifetime Frequency of } \\
\text { Cannabis Use } \\
\text { Among Users }\end{array}$} \\
\hline At weekends or less & $50(26.1)$ & $73(60.5)$ & 1 & \\
\hline Everyday & $138(73.9)$ & $48(39.5)$ & & $<.001$ \\
\hline No details & 90 & 39 & & \\
\hline
\end{tabular}

FEP, first episode psychosis patients.

${ }^{a} p$ values from $\chi^{2}$ tests.

subjects $\left(\chi^{2}=1.25 ; p=.535\right)$. In addition, we found no difference in the frequency of the AKT1 rs2494732 polymorphism across ethnic groups $\left(\chi^{2}=3.01 ; p=.87\right)$. Genotypes at rs2494732 were in HardyWeinberg equilibrium within ethnically stratified control subjects $(p=.639)$.

\section{Drug Consumption}

More than two thirds (68.6\%) of the FEP patients had a history of smoking tobacco compared with $46.8 \%$ of the control subjects $\left(\chi^{2}=9.3 ; p<.001\right)$. However, the two groups did not differ in the number of alcohol units consumed weekly $\left(\chi^{2}=6.4 ; p=.095\right)$, the prevalence of life time cannabis use $\left(\chi^{2}=.3 ; p=.567\right)$, or on the use of stimulant drugs $\left(\chi^{2}=2.1 ; p=.146\right)$. The proportion of FEP (36.2\%) who reported current cannabis use was slightly, but nonsignificantly, higher $\left(\chi^{2}=3.0 ; p=.085\right)$ than control subjects $(27.1 \%)$. We measured the reliability of the self-reported data on current user status in a random sample of 56 cases, carrying out a urinary drug screening. Of the 56 cases tested, 34 had reported they were not current users; 32 of these $(88 \%)$ had a negative urinary drug screening; only 2 tested positive and these were excluded from the analyses.

Among those who had a history of lifetime cannabis use, FEP were more likely than control subjects to be male $\left(\chi^{2}=11.8 ; p=\right.$ .001 ), to be younger (mean age 26.9 years, SD 7.8 vs. mean age 29.7 years, SD $8.6 ; t=3.1 ; p<.001)$, and to report daily use $(73.9 \%$ vs. $39.5 \% ; \chi^{2}=35.8 ; p<.001$ ) (Table 2 ).

\section{Case-Control $\mathbf{G} \times \mathbf{E}$ Analyses}

There was no evidence of a correlation between the AKT1 rs2494732 genotype and lifetime cannabis use $\left(\chi^{2}=.7, p=.692\right)$ or lifetime frequency of use $\left(\chi^{2}=4.4 ; p=.352\right)$.

A multivariable logistic regression adjusting for gender, ethnicity, and tobacco use $(n=598)$ showed a significant interaction between lifetime cannabis use and genotype (likelihood ratio test $=8.54 ; p=.014)$. This suggests that the effect of lifetime cannabis use on the likelihood of suffering from a psychotic disor- 


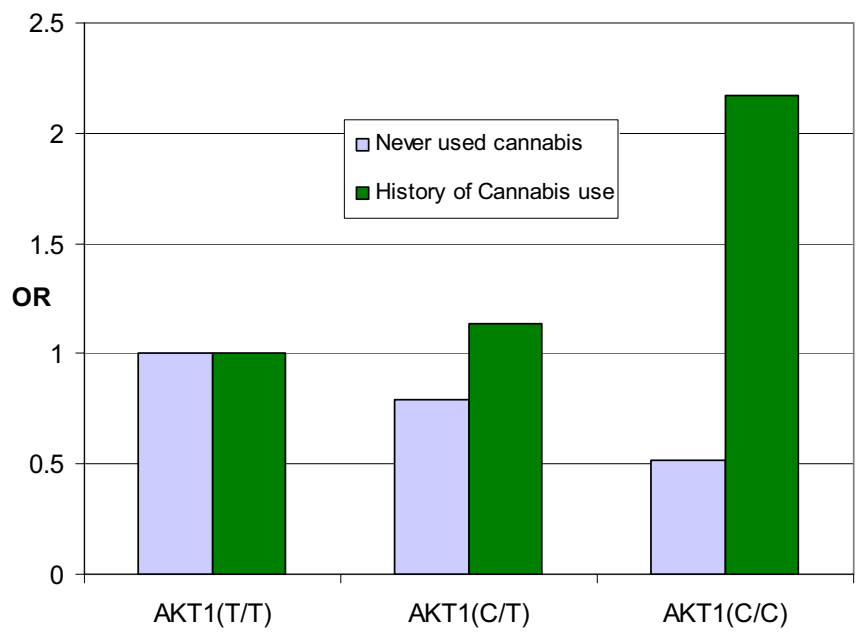

Figure 2. Odds ratio (OR) of psychosis for subjects with AKT1 rs $2494732 \mathrm{C} / \mathrm{T}$ or $\mathrm{C} / \mathrm{C}$ genotype compared to $\mathrm{T} / \mathrm{T}$, according to their cannabis use.

der differed according to rs2494732 genotype. Among those who had never used cannabis, there was no significant change in risk associated with rs 2494732 genotype. In contrast, among subjects having a lifetime history of cannabis use, carriers of the C/C genotype showed a greater than twofold increased odds of having psychotic disorder (OR $=2.18 ; 95 \%$ confidence interval: 1.10, 4.31) when compared with T/T carriers (Figure 2; Table 3).

In a second logistic regression, which again controlled for the same covariates as above $(n=511)$, we found the interaction between the AKT1 rs2494732 genotype and lifetime frequency of cannabis use to be significant at greater than the $5 \%$ level (likelihood ratio test $=13.39 ; p=.010$ ). Among subjects who had never used cannabis, there was again no significant association between genotype and presence of a psychotic disorder. In contrast, among both occasional and daily cannabis users, the OR for $\mathrm{C} / \mathrm{C}$ carriers indicated an increase in the probability of suffering a psychotic disorder in comparison with those with the T/T genotype, but only among daily cannabis users did the increased odds of psychosis shown by $\mathrm{C} / \mathrm{C}$ carriers reach significance $(\mathrm{OR}=7.23$; $95 \%$ confidence interval: 1.37, 38.12) (Figure 3; Table 4).

\section{Discussion}

Although only a minority of cannabis users ever develop a psychotic disorder, its widespread use means that it is important to establish why some individuals develop the illness. Our previous study showed that the risk of psychosis depends, in part, on how frequently people use cannabis (23). Our present findings confirm the recent report of the role played by the variation at the rs2494732 locus of $A K T 1$ in influencing the risk of cannabis use in causing psychosis (12). This opens up the possibility of identifying those who should avoid the use of cannabis.

Table 3. Odds Ratio of Psychosis Among Cannabis Users with $\mathrm{C} / \mathrm{T}$ or $\mathrm{C} / \mathrm{C}$ Genotype Compared with T/T

\begin{tabular}{lccc}
\hline AKT1 rs249432 Genotype Variants & Adjusted OR $^{a}$ & $95 \% \mathrm{Cl}$ & $p$ Value \\
\hline T/T & 1 & - & \\
C/T & 1.15 & $.67,1.96$ & .616 \\
C/C & 2.18 & $1.10,4.31$ & .025 \\
\hline
\end{tabular}

$\mathrm{Cl}$, confidence interval; $\mathrm{OR}$, odds ratio.

${ }^{a}$ Adjusted for gender, ethnicity, and tobacco use.

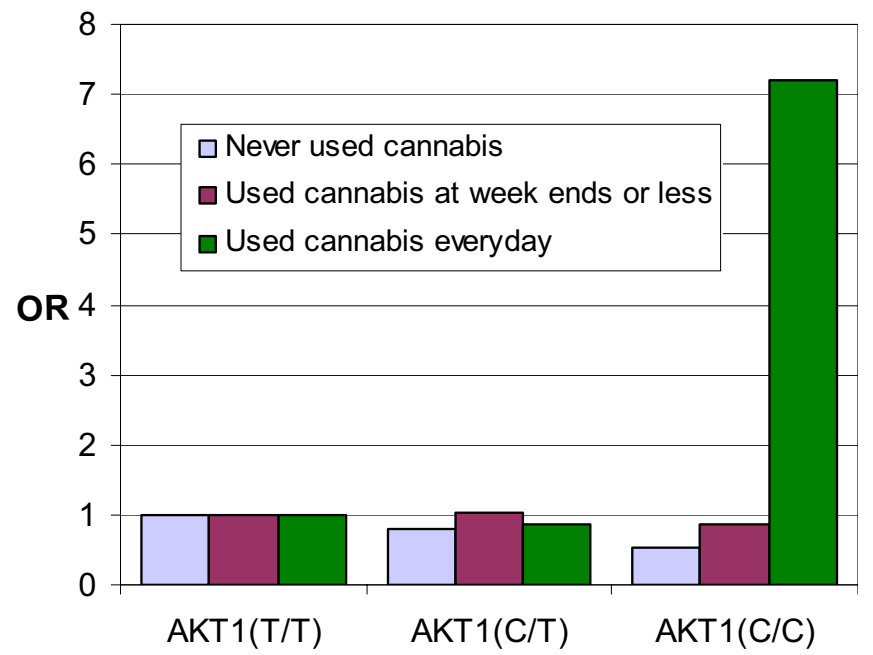

Figure 3. Odds ratio (OR) of psychosis for $A K T 1 \mathrm{rs} 2494732 \mathrm{C} / \mathrm{T}$ or $\mathrm{C} / \mathrm{C}$ carriers compared to subjects with the T/T genotype depending on lifetime frequency of cannabis use.

The biology of cannabis-induced psychosis is only partly understood (24). The active ingredient of cannabis, delta-9-TCH, is responsible for its psychotomimetic effects. Delta-9-tetrahydrocannabinol inhibits, via cannabinoid receptor type 1 activation, the release of glutamate onto gamma-aminobutyric acidergic neurons that project from the nucleus accumbens to the ventral tegmental area. These neurons normally exert an inhibitory effect on the firing of dopamine neurons that project back to the nucleus accumbens (25). Thus, their inhibition causes increased dopamine release in the striatum, which is implicated in the pathogenesis of psychotic symptoms $(26,27)$.

It seems logical to attempt to explain differences in the individual response to the psychotogenic effects of cannabis in terms of individual genetic makeup, particularly the subset of genes involved in dopamine pathways. However, an early report that variation at the COMT gene might play a role remains controversial $(4,28)$.

Nevertheless, genes that regulate signaling pathways and impact on dopamine transmission may still be plausible candidates for such a $\mathrm{G} \times \mathrm{E}$ interaction. For instance, the protein encoded by the gene $A K T 1$ is a serine/threonine kinase, whose main function is the phosphorylation and consequent inactivation of glycogen synthase kinase (GSK-3) (26). AKT1 and GSK-3 are known to be at the heart of a signal transduction framework, initiated by dopamine D2 signaling, which ultimately influences a wide range of cellular processes, including apoptosis, cell survival, and metabolism (29). A recent neuroimaging study by Blasi et al. (30) showed that AKT1/ $D R D 2$ polymorphisms are epistatically associated with attentional processing and response to olanzapine treatment in schizophrenia. These findings further support the role of the AKT1 pathway in regulating D2 receptor dependent dopamine signaling and its role in psychotic disorders.

Moreover, in vivo studies have reported that delta-9-THC can induce phosphorylation of $A K T 1$ with its activation in several brain areas, including the striatum (31). As the activation of the AKT1/ GSK-3 cascade is known to impact on D2 receptor signaling $(32,33)$, it is plausible that delta-9-THC might increase liability to psychosis via this pathway. Our findings need to be considered in light of some potential limitations.

First, it is possible that our method of control subject recruitment could have biased our findings. However, there is no sugges- 
Table 4. Odds Ratio of Psychosis for C/T or C/C Carriers Compared with Subjects with the T/T Genotype Depending on Their Lifetime Frequency of Cannabis Use

\begin{tabular}{|c|c|c|c|c|c|c|c|c|c|}
\hline \multirow{2}{*}{$\begin{array}{l}\text { AKT1 rs249432 } \\
\text { Genotype } \\
\text { Variants }\end{array}$} & \multicolumn{3}{|c|}{ Never Used } & \multicolumn{3}{|c|}{ Used Cannabis at Weekends or Less } & \multicolumn{3}{|c|}{ Used Cannabis Every Day } \\
\hline & Adjusted OR ${ }^{a}$ & $95 \% \mathrm{Cl}$ & $p$ Value & Adjusted OR ${ }^{a}$ & $95 \% \mathrm{Cl}$ & $p$ Value & Adjusted OR ${ }^{a}$ & $95 \% \mathrm{Cl}$ & $p$ Value \\
\hline $\mathrm{T} / \mathrm{T}$ & 1 & - & & 1 & - & & 1 & - & \\
\hline $\mathrm{C} / \mathrm{T}$ & .80 & $.39,1.62$ & .532 & 1.04 & $.41,2.66$ & .928 & .87 & $.36,2.12$ & .766 \\
\hline $\mathrm{C} / \mathrm{C}$ & .53 & $.24,1.16$ & .114 & .86 & $.26,2.80$ & .803 & 7.23 & $1.37,38.12$ & .020 \\
\hline
\end{tabular}

$\mathrm{Cl}$, confidence interval; OR, odds ratio.

${ }^{a}$ Adjusted for gender, ethnicity, and tobacco use.

tion that we undersampled cannabis users. Indeed, the proportion of control subjects that had ever used cannabis (63\%) was higher than the national average (47\%) for similar age groups. This is probably a reflection of the higher prevalence of cannabis use in the local community compared with the United Kingdom as a whole (34). Almost equal prevalence of exposure in both cases and control subjects increases the power of $G \times E$ analyses. It is possible that our control subject recruitment strategy biased our sample toward one of mild cannabis users. Our advertising strategy included internet and local newspapers ads, as well as distribution of leaflets at local shops, job centers, and community centers. There is no evidence that such methods of advertising are more likely to bias toward better functioning and socially adjusted subjects; indeed, the opposite might happen. Therefore, it seems unlikely that the difference in frequency of cannabis use by cases and control subjects is driven by a recruitment bias.

Second, our sample is multiethnic. This could be limiting, given that HapMap reports the following differences in allele frequency between populations: Black African: .42, White Caucasian: .46, Asian (Chinese and Japanese): .62 (35). To account for the possibility of population stratification, we controlled for the potential confounding effect of ethnicity. However (as already reported), we could find no actual difference between the frequency of rs2494732 alleles across the main (black and white caucasian) ethnic groups (in cases and control subjects) (Table 5). This is consistent with HapMap data and the marginal difference between the minor allele frequency estimates themselves in African and Caucasian populations (.42 vs. .46), compared with Chinese and Japanese. Our sample comprised just three cases and two control subjects of Chinese and Japanese origin. Thus, latent differences in allele frequency at rs2494732 were very unlikely to have biased the outcome of the study.

Another possible limitation is the lack of evidence that variation at the locus of our AKT1 SNP of interest (rs2494732) affects the signaling pathway. There are no available data describing if and how changes in the AKT1 genotype for rs2494732 impact on the protein function. Nevertheless, HapMap 3 preliminary data report (36) that rs2494732 is 702 base pairs apart from rs1130233, a SNP that has been shown to affect AKT gene messenger RNA expression (37). The $R^{2}$ (a measure of correlation) between these two SNPs (rs2494732 and rs1130233) is .95, which genetically speaking is very high and suggestive of linkage dysequilibrium. This might explain why the studies that have tested for an AKT1-cannabis interaction on either a psychosis outcome $(12,14)$ or altered cognitive performance (13) have converged in the same direction whether selecting rs2494732 or rs1130233 as the genetic variant of interest.

Finally, we relied on self-report concerning cannabis use. We did, however, check the urine of a subsample and found concordance of the two methods in a very high proportion of cases. Furthermore, any inaccuracy would have diminished our likelihood of finding an interaction effect.

The main strength of our study is its design. A case-control strategy is the gold standard design to test $G \times E$ interaction hypotheses (38). In addition, in keeping with good methodological practice for a $\mathrm{G} \times \mathrm{E}$ replication study (39), we genotyped only the candidate genetic variant and selected the environmental exposure according to the priori hypothesis suggested by the original report (12) we set to replicate; thus, we avoided multiple testing.

Our study sample size had $70 \%$ power to detect, at a 5\% significance level, the twofold increased likelihood of psychotic disorder in AKT1 rs2494732 C/C carriers with history of cannabis use compared with T/T carriers. Importantly, it had over $80 \%$ power to detect the sevenfold increase in OR we report in AKT1 rs2494732 $\mathrm{C} / \mathrm{C}$ carriers who used cannabis daily compared with the T/T ones. In the original report, van Winkel et al. (12) also noted a significant interaction between frequency of use, as a measure of exposure to cannabis, and AKT1 rs2494732, which further indicates that our results are a true replication.

In conclusion, our findings confirm the moderating role of the AKT1 rs 2494732 C/C genotype on the effect of cannabis use in increasing the risk of a psychotic disorder.

Nevertheless, genome-wide association studies have shown that the term polygenic can refer to hundreds or thousands of common variants (40). Therefore, it is likely that AKT1 rs 2494732 contributes to susceptibility to the psychotogenic effect of cannabis together with other genetic variants. Indeed, a recent report shows that five of the novel schizophrenia loci identified by the Schizophrenia Psychiatric Genome-Wide Association Study Consortium impact on the AKT pathway and concludes that these

Table 5. This Shows No Significant Difference in the AKT1 rs 2494732 Allelic Distributions by Ethnicity in Control Group

\begin{tabular}{|c|c|c|c|c|c|c|}
\hline \multirow[b]{2}{*}{ Ethnicity } & \multicolumn{3}{|c|}{$\begin{array}{l}\text { AKT1 rs2494732 Genotype Frequency in Control } \\
\text { Subjects }(n=265)(\%)\end{array}$} & \multicolumn{2}{|c|}{ Allelic Frequency } & \multirow{2}{*}{$\begin{array}{l}\text { Hardy-Weinberg } \\
\qquad p \text { Value }^{a}\end{array}$} \\
\hline & $\mathrm{T} / \mathrm{T}$ & $\mathrm{C} / \mathrm{T}$ & $\mathrm{C} / \mathrm{C}$ & $\mathrm{T}$ & C & \\
\hline White Caucasian & $49(34)$ & $71(49)$ & $25(17)$ & $169(.58)$ & $121(.42)$ & Nonsignificant \\
\hline Black Caribbean & $14(26)$ & $27(51)$ & $12(23)$ & $55(.52)$ & $51(.48)$ & Nonsignificant: .08 \\
\hline Black African & $4(13)$ & $18(60)$ & $8(27)$ & $26(.43)$ & $34(.57)$ & Nonsignificant \\
\hline Asian/Others & $15(40)$ & $11(30)$ & $11(30)$ & $41(.55)$ & $33(.45)$ & Nonsignificant \\
\hline
\end{tabular}

\footnotetext{
${ }^{a} p$ values from $\chi^{2}$ test.
} 
genes may be involved in "converting information from the environment to this biological system" (8). Identifying such gene variants and the biological pathways they influence can improve our understanding on how they exert their effect on an individual's liability to psychosis in the presence of particular environmental risk factors. This should help us to design health, educational, and screening campaigns tailored to reach those groups at particular risk.

This project was developed in collaboration with the Genetic and Psychotic Disorders Study and PUMP study teams and the South London and Maudsley Mental Health National Health Service trust. Funding was provided by the United Kingdom National Institute of Health Research Specialist Biomedical Research Centre for Mental Health, South London and Maudsley National Health Service Foundation Trust, and the Institute of Psychiatry at King's College London; The Psychiatry Research Trust; and the Maudsley charity research fund. Supported by the European Community's Seventh Framework Program under grant agreement No. HEALTHF2-2009-241909 (Project EU-GEI).

The authors report no biomedical financial interests or potential conflicts of interest.

\section{Supplementary material cited in this article is available online.}

1. United Nations Office on Drugs and Crime (2009): UNODC World Drug Report 2009.

2. Henquet C, Murray R, Linszen D, van Os J (2005): The environment and schizophrenia: The role of cannabis use. Schizophr Bull 31:608-612.

3. Moore TH, Zammit S, Lingford-Hughes A, Barnes TR, Jones PB, Burke M, Lewis $G$ (2007): Cannabis use and risk of psychotic or affective mental health outcomes: A systematic review. Lancet 370:319-328.

4. Caspi A, Moffitt TE, Cannon M, McClay J, Murray R, Harrington H, et al. (2005): Moderation of the effect of adolescent-onset cannabis use on adult psychosis by a functional polymorphism in the catechol-O-methyltransferase gene: Longitudinal evidence of a gene $x$ environment interaction. Biol Psychiatry 57:1117-1127.

5. Henquet C, Rosa A, Krabbendam L, Papiol S, Fananas L, Drukker M, et al. (2006): An experimental study of catechol-o-methyltransferase Val158Met moderation of delta-9-tetrahydrocannabinol-induced effects on psychosis and cognition. Neuropsychopharmacology 31:2748-2757.

6. Thiselton DL, Vladimirov VI, Kuo PH, McClay J, Wormley B, Fanous A, et al. (2008): AKT1 is associated with schizophrenia across multiple symptom dimensions in the Irish study of high density schizophrenia families. Biol Psychiatry 63:449-457.

7. Karege F, Meary A, Perroud N, Jamain S, Leboyer M, Ballmann E, et al. (2012): Genetic overlap between schizophrenia and bipolar disorder: A study with AKT1 gene variants and clinical phenotypes. Schizophr Res 135:8-14.

8. Bolog Z, Kiss I, Bolcs KM (2012): New schizophrenia loci may converge on the same cellular mechanism: The AKT pathway. Am J Psychiatry 169:3.

9. Bozzi Y, Dunleavy M, Henshall DC (2011): Cell signaling underlying epileptic behavior. Front Behav Neurosci 5:45.

10. Ozaita A, Puighermanal E, Maldonado R (2007): Regulation of PI3K/Akt/ GSK-3 pathway by cannabinoids in the brain. J Neurochem 102:1105-1114

11. Gomez del Pulgar T, Velasco G, Guzman M (2000): The CB1 cannabinoid receptor is coupled to the activation of protein kinase B/Akt. Biochem J 347:369-373.

12. van Winkel R (2011): Family-based analysis of genetic variation underlying psychosis-inducing effects of cannabis: Sibling analysis and proband follow-up. Arch Gen Psychiatry 68:148-157.

13. van Winkel R, van Beveren NJ, Simons C, Genetic Risk and Outcome of Psychosis (GROUP) Investigators (2011): AKT1 moderation of cannabisinduced cognitive alterations in psychotic disorder. Neuropsychopharmacology 36:2529-2537.

14. Bhattacharyya S, Atakan Z, Martin-Santos R, Crippa JA, Kambeitz J, Prata $D$, et al. (2012): Preliminary report of biological basis of sensitivity to the effects of cannabis on psychosis: AKT1 and DAT1 genotype modulates the effects of d-9-tetrahydrocannabinol on midbrain and striatal function [published online ahead of print January 31]. Mol Psychiatry.

15. Duncan LE, Keller MC (2011): A critical review of the first 10 years of candidate gene-by-environment interaction research in psychiatry. Am J Psychiatry 168:1041-1049.
16. World Health Organization (1992): International Classification of Diseases, 10th Edition (ICD-10): Classification of Mental and Behavioural Disorders. Geneva: World Health Organization.

17. World Health Organization (1992): Schedules for Clinical Assessment in Neuropsychiatry (SCAN). Geneva: World Health Organization.

18. Office for National Statistics (2011): 2011 Census. Available at: www. statistics.gov.uk/census.

19. Bebbington P, Nayani T (1995): The Psychosis Screening Questionnaire. Int J Methods Psychiatr Res 5:11-19.

20. Mallett R, Leff J, Bhugra D, Pang D, Zhao JH (2002): Social environment, ethnicity and schizophrenia. A case-control study. Soc Psychiatry Psychiatr Epidemiol 37:329-335.

21. Di Forti M, Morgan C, Dazzan P, Pariante C, Mondelli V, Marques TR, et al. (2009): High-potency cannabis and the risk of psychosis. Br J Psychiatry 195:488-491.

22. Falush D, Stephens M, Pritchard JK (2003): Inference of population structure using multilocus genotype data: Linked loci and correlated allele frequencies. Genetics 164:1567-1587.

23. Morrison PD, Murray RM (2009): From real-world events to psychosis: The emerging neuropharmacology of delusions. Schizophr Bull 35:668-674.

24. Adermark L, Talani G, Lovinger DM (2009): Endocannabinoid-dependent plasticity at GABAergic and glutamatergic synapses in the striatum is regulated by synaptic activity. Eur J Neurosci 29:32-41.

25. Laruelle M, Abi-Dargham A (1999): Dopamine as the wind of the psychotic fire: New evidence from brain imaging studies. J Psychopharmacol 13:358-371.

26. Abi-Dargham A, Rodenhiser J, Printz D, Zea-Ponce Y, Gil R, Kegeles LS, et al. (2000): Increased baseline occupancy of D2 receptors by dopamine in schizophrenia. Proc Natl Acad Sci U S A 97:8104-8109.

27. Zammit S, Spurlock G, Williams H, Norton N, Williams N, O'Donovan MC, Owen MJ (2007): Genotype effects of CHRNA7, CNR1 and COMT in schizophrenia: Interactions with tobacco and cannabis use. Br J Psychiatry 191:402-407.

28. Cross DA, Alessi DR, Cohen P, Andjelkovich M, Hemmings BA (1995): Inhibition of glycogen synthase kinase-3 by insulin mediated by protein kinase B. Nature 378:785-789.

29. Scheid MP, Woodgett JR (2011): PKB/AKT: Functional insights from genetic models. Nat Rev Mol Cell Biol 2:760-768.

30. Blasi G, Napolitano F, Ursinia G, Taurisano P, Romanoa R, Caforio G, et al. (2011): DRD2/AKT1 interaction on D2 c-AMP independent signaling, attentional processing, and response to olanzapine treatment in schizophrenia. Proc Natl Acad Sci U S A 108:1158-1163.

31. Sanchez MG, Ruiz-Llorente L, Sanchez AM, Diaz-Laviada I (2003): Activation of phosphoinositide 3-kinase/PKB pathway by $\mathrm{CB}(1)$ and $\mathrm{CB}(2)$ cannabinoid receptors expressed in prostate PC-3 cells. Involvement in Raf-1 stimulation and NGF induction. Cell Signal 15:851-859.

32. Beaulieu JM, Gainetdinov RR, Caron MG (2007): The Akt-GSK-3 signaling cascade in the actions of dopamine. Trends Pharmacol Sci 28:166-172.

33. Beaulieu JM, Tirotta E, Sotnikova TD, Masri B, Salahpour A, Gainetdinov RR, et al. (2007): Regulation of Akt signaling by D2 and D3 dopamine receptors in vivo. $J$ Neurosci 27:881-885.

34. British Crime Survey (2007/2008): Crime Surveys Programme Research Development and Statistics Crime Reduction and Community Safety Group Home Office.

35. National Center for Biotechnology Information (2012): dbSNP Short Genetic Variations. Available at www.ncbi.nlm.nih.gov/projects/SNP. Accessed February 2012.

36. The International HapMap 3 Consortium, Altshuler DM, Gibbs RA, Peltonen L, Altshuler DM, Gibbs RA, et al. (2012): Integrating common and rare genetic variation in diverse human populations. Nature 467:52-58.

37. Tan H-Y, Nicodemus KK, Chen Q, Li Z, Brooke JK, Honea R, et al. (2008). Genetic variation in AKT1 is linked to dopamine-associated prefrontal cortical structure and function in humans. J Clin Invest 118:2200-2208.

38. Khoury MJ, Flanders WD (1996): Non traditional epidemiologic approaches in the analysis of gene-environment interaction: Case-control studies with no controls! Am J Epidemiol 144:207-213.

39. Moffitt TE, Caspi A, Rutter M (2005): Strategy for investigating interactions between measured genes and measured environments. Arch Gen Psychiatry 62:473-481.

40. International Schizophrenia Consortium, Purcell SM, Wray NR, Stone JL, Visscher PM, O'Donovan MC, et al. (2009): Common polygenic variation contributes to risk of schizophrenia and bipolar disorder. Nature 460: $748-752$. 